\title{
Freshwater fishes of Tsitsikamma National Park
}

\section{I.A. RUSSELL}

Russell, I.A. 2002. Freshwater fishes of Tsitsikamma National Park. Koedoe 45(2): 13-17. Pretoria. ISSN 0075-6458.

This study aimed to determine the distribution and relative abundance of freshwater fishes in the Tsitsikamma National Park. Fish assemblages in six river systems were sampled in 2001, with a total of 323 fish from eight species recorded. Indigenous fish collected included four freshwater species (Pseudobarbus afer, Pseudobarbus tenuis, Sandelia capensis, Anguilla mossambica), three estuarine species (Monodactylus falciformis, Caffrogobius gilchristi, Myxus capensis), and one alien (Micropterus salmoides). One additional indigenous species (Galaxias zebratus) and two aliens (Salmo trutta, Oncorhynchus mykiss) could potentially occur within the park. The topography and locality of the park presents a unique opportunity to meaningfully conserve the Endangered $P$. tenuis as well as other fish characteristic of the eastern reaches of the Cape Floristic Region. Management action is required to minimise opportunities for further establishment and spread of alien fish species and to conserve indigenous fish assemblages within the park.

Key words: freshwater fish, diversity, alien, conservation, Tsitsikamma, Keurbooms.

\section{I.A. Russell, South African National Parks, P.O. Box 176, Sedgefield, 6573, Republic of South Africa.}

\section{Introduction}

Rivers in the Cape Floristic Region (CFR) of the Western and Eastern Cape provinces of South Africa harbour a distinctive fish fauna, characterised with a high level of endemicity (16 of 19 species) (Skelton 1987). The freshwater fishes of the CFR are also highly threatened, with 15 species (79\%) being Red-Data listed, nine of which are classed as either Endangered or Critically Endangered (Hilton-Taylor 2000), and are reliant on effective conservation of the region for their survival (Impson et al. 2001).

The Tsitsikamma National Park (TNP) is located in the eastern reaches of the CFR, with recently acquired and contractually managed areas containing river systems which drain catchments supporting predominantly afromontane forest (Von Breitenbach 1974) and both wet and mesic mountain fynbos (Moll \& Bossi 1984). The TNP thus has the potential to contribute to the conservation of the ichthyofauna of the Cape Floristic Region. The only published account of the freshwater fishes of TNP lists three species
(Anguilla mossambica, Pseudobarbus asper and Sandelia capensis) as occurring in the park (Smith \& Smith 1966). Sampling undertaken in rivers in the Tsitsikamma area outside the park's boundaries has revealed a more diverse ichthyofauna (Le Roi Le Riche \& Hey 1947; Scott \& Hamman 1984; Skelton 1980; Skelton 1988; unpublished records from Albany Museum and South African Institute for Aquatic Biodiversity). Of particular conservation interest is the occurrence of Pseudobarbus tenuis, classified as Endangered (Hilton-Taylor 2000), in rivers of the Keurbooms system outside the current national park boundaries. The objective of this study was to describe the distribution and relative abundance of freshwater fish in TNP, with particular attention being given to assessing the status of $P$. tenuis.

\section{Methods}

Fish sampling was undertaken in February and March 2001. Rivers in the TNP are generally small, shallow and with a stony substratum, thus all sam- 
pling was undertaken using an electro-fishing apparatus. A hand-held electric fish shocker, powered by a $220 \mathrm{~V} \mathrm{AC,} 2-\mathrm{kVa}$ portable generator was used at sample sites that were located close to access roads. At sites that were far removed from access roads a portable 12V DC electric fish shocker (Deka 3000) was used to sample fish, which although less effective than the AC powered unit, was more easily portaged for long distances over broken terrain.

All fish collected were identified using identification keys in Skelton (1993). Voucher specimens were preserved in either $10 \%$ formalin or $70 \%$ alcohol, and housed at the South African Institute for Aquatic Biodiversity in Grahamstown (Caffrogobius gilchristi $=$ RUSI 64253; Monodactylus falciformis $=$ RUSI 64254; Myxus capensis = RUSI 64255; Anguilla mossambica = RUSI 64256; Micropterus salmoides = RUSI 64257; Pseudobarbus asper group $=$ RUSI 64258; Pseudobarbus afer $=$ RUSI 64259-60; Pseudobarbus tenuis = RUSI 64261-66).

\section{Results}

A total of 323 fish from at least eight species was recorded (Table 1). All specimens classified as Pseudobarbus spp. (Table 1) were juveniles that were too small to enable identification to species level based on anatomical features. All unidentified specimens were collected in the lower reaches of the Groot (West) River in the presence of adult $P$. afer. Of the eight positively identified species, three (M. falciformis, C. gilchristi, M. capensis) occur predominantly in estuaries or inshore coastal waters although are occasionally found in coastal rivers (Skelton 1993), and one species (M. salmoides) is an alien. Pseudobarbus afer and S. capensis were collected only in the Groot (West) River, whereas $P$. tenuis was found to be restricted to the Keurbooms system. Anguilla mossambica was the only freshwater fish recorded in both the Sout and Brak rivers.

\section{Discussion}

Published accounts of fish in the Keurbooms system, and collections of preserved fish specimens from the Groot (West) and Keurbooms systems, housed in the Albany Museum and the South African Institute for Aquatic Biodiversity, indicate the possible occurrence of three additional species in the Tsitsikamma National Park. The first is the Cape Galaxias Galaxias zebratus, which has been recorded in several tributaries of the Keurbooms system, including the Palmiet River westward of the Soetkraal portion of TNP (Fig. 1). Skelton (1993) describes $G$. zebratus as being able to tolerate a wide range of water and temperature conditions, and there is no obvious reason why it should not occur in the eastern tributaries of the Keurbooms system in the Tsitsikamma National Park. Cambray et al. (1995) recorded G. zebratus from the upper reaches of the

Table 1

Number of fish specimens per species collected per site in the Tsitsikamma National Park during February and March 2001. Site numbers as per Figure 1. Sampling effort = minutes electro-fishing

\begin{tabular}{|c|c|c|c|c|c|c|c|c|c|c|c|c|c|}
\hline \multicolumn{2}{|l|}{$\begin{array}{l}\text { Site number } \\
\text { Sampling Effort }\end{array}$} & $\begin{array}{r}1 \\
155\end{array}$ & $\begin{array}{r}2 \\
60\end{array}$ & $\begin{array}{r}3 \\
10\end{array}$ & $\begin{array}{r}4 \\
30\end{array}$ & $\begin{array}{r}5 \\
120\end{array}$ & $\begin{array}{r}6 \\
45\end{array}$ & $\begin{array}{r}7 \\
30\end{array}$ & $\begin{array}{r}8 \\
20\end{array}$ & $\begin{array}{r}9 \\
40\end{array}$ & $\begin{array}{l}10 \\
20\end{array}$ & $\begin{array}{l}11 \\
20\end{array}$ & Total \\
\hline Anguilla mossambica & Longfin eel & 12 & 1 & - & 1 & 4 & 3 & 1 & - & - & & - & 22 \\
\hline Pseudobarbus afer & Eastern Cape Redfin & 27 & - & 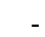 & - & - & & & - & - & & - & 27 \\
\hline Pseudobarbus spp. & Redfin species & 124 & - & - & - & - & - & - & - & - & - & - & 124 \\
\hline Pseudobarbus tenuis & Slender Redfin & - & 16 & 3 & 35 & - & - & - & - & - & - & - & 54 \\
\hline erus salmoides & Large & - & - & - & - & - & - & - & - & 33 & 1 & - & 34 \\
\hline Sandelia capensis & Cape 1 & 2 & - & - & - & - & - & - & - & - & - & ـ & 2 \\
\hline Myxus capensis & Freshwater Mullet & - & - & - & - & 20 & - & - & - & - & - & - & 20 \\
\hline Monodactylus falciformis & Cape Moony & - & - & - & - & 33 & - & - & - & - & - & - & 33 \\
\hline Caffrogobius gilchristi & Prison Goby & - & - & - & - & 7 & - & - & - & - & - & - & 7 \\
\hline \multicolumn{2}{|l|}{ Total number of individuals } & 165 & 17 & 3 & 36 & 64 & 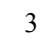 & & & 33 & & 0 & 323 \\
\hline \multicolumn{2}{|l|}{ Total number of species } & 3 & 2 & 1 & 2 & 4 & 1 & 1 & 0 & 1 & 1 & 0 & 9 \\
\hline
\end{tabular}




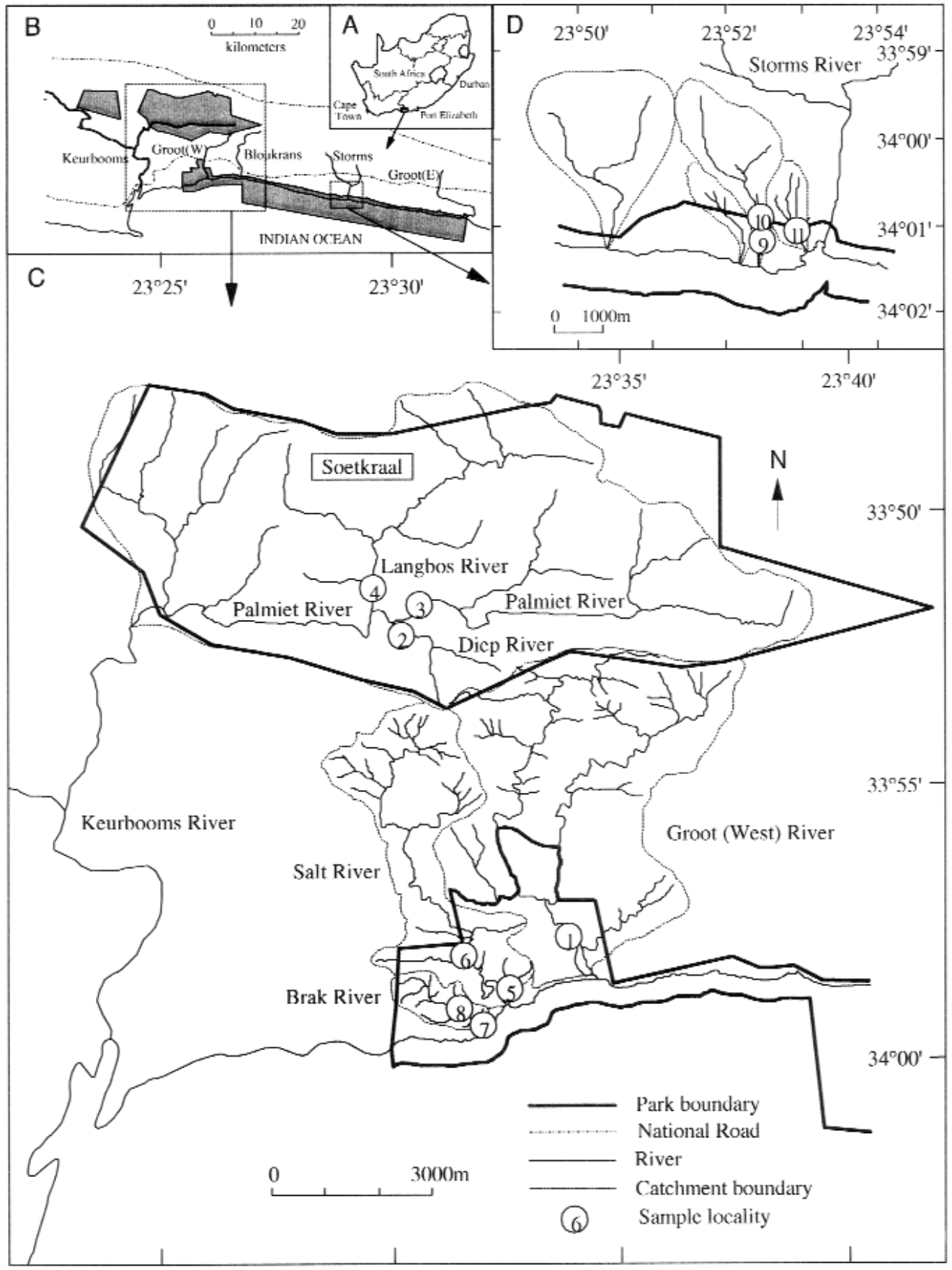

Fig 1. Location of the Tsitsikamma National Park relative to major centres (A) and geographical features (B), and location of study sites in the Keurbooms, Salt, Brak and Groot (West) rivers (C) and two unnamed rivers in the vicinity of the Storms River (D). 
Krom and Gamtoos rivers eastward of TNP. It is thus possible that G. zebratus could also occur in rivers eastward of the Keurbooms system in the park. The other two species, which could also potentially occur in TNP by virtue of their having previously been collected in the Keurbooms system, are the Brown Trout Salmo trutta, and Rainbow Trout Oncorhynchus mykiss. Salmo trutta was described by DeMoor \& Bruton (1988) as "thriving" in the Keurbooms River despite the supposed intolerance of this species of low $\mathrm{pH}$, peat-stained rivers characteristic of the southern Cape coastline. Skelton (1994) recorded $O$. mykiss in the mainstream of the upper reaches of the Keurbooms River. The current status of both $S$. trutta and $O$. mykiss in the Keurbooms River is unknown, though their preference for mountain or upland streams (Skelton 1993) means that they pose a threat to invasion of the upper reaches of the Palmiet River in the park.

This study confirms the findings of surveys undertaken in 1925 (Hey 1926) and 2000/2001 (A. Bok pers. comm.) that no freshwater fish other than eels occur in the Salt River, and suggests that a similar absence occurs in the smaller Brak River. The absence of cyprinids from the Brak River is possibly a consequence of episodic flow, with at the time of sampling the Brak River consisting of a series of isolated stagnant pools, conditions not ideal for Pseudobarbus species indigenous to the area (Skelton 1993). The absence of most expected freshwater fish, and in particular $P$. afer, from the Salt River, however, is from an ecological perspective difficult to explain. Local knowledge indicates that the Salt River is perennial, and aquatic habitats in the river appear highly suitable for Pseudobarbus species, which are found in similar adjacent rivers. It is unknown what influence this largely 'fish-less' state of the Salt River has had on other aquatic biota. Preliminary surveys of aquatic invertebrates have indicated a diverse community with several endemics, and at least three previously undescribed genera and 11 undescibed species (F. De Moor pers. comm.). From a conservation standpoint the temptation to introduce fish, particularly aliens, into the Salt River should be resisted in the interests of conserving what is potentially a unique aquatic ecosystem.

Impson et al. (2001) suggest that national parks in the CFR make a negligible contribution to the conservation of indigenous fishes, with only two species recorded in parks. This study along with recent surveys (Russell, 1998, 1999, 2001), however, indicate that rivers in national parks contain populations of at least eight of the 19 fish species indigenous to the CFR, and hence make a moderate contribution to the conservation of these biota. The TNP in particular provides a unique opportunity to meaningfully conserve the Endangered (Hilton-Taylor 2000) P. tenuis. With respect to rivers in the Soetkraal section, TNP has several of the attributes identified by Skelton et al. (1995) as necessary for effective conservation of riverine fishes, namely (i) it is positioned high in the catchment, (ii) encompasses the entire upper catchment of the affected area, in this case the Palmiet River, and (iii) highimpact alien predators do not occur within the reserve. The remaining requirements for effective conservation of (iv) maintaining natural hydrological cycles, and (v) securing the minimum water quantity and quality requirements of the entire biotic community are either already being achieved, or could potentially be achieved through continued eradication of alien plants in the upper Palmiet River catchment area. An alien plant removal program operating under the auspices of the Working for Water program of the South African Department of Water Affairs and Forestry has been active in the Keurbooms River catchment since 1995, and plans have been formulated to continue the program till at least 2008 (Gelderblom \& Rowlinson 1999) demonstrating an ongoing commitment to rehabilitate this catchment.

Possibly one of the greatest threats to $P$. tenuis and other indigenous fishes in the Keurbooms system is the introduction or spread of alien predatory fish. Salmo trutta and $O$. mykiss have previously been recorded in the Keurbooms River (unpublished 
records from the South African Institute for Aquatic Biodiversity; Skelton 1994), and this study has demonstrated that Largemouth Black Bass $M$. salmoides have become established in adjacent streams. A threat is also posed by the interest shown by landowners adjacent to TNP to continue stocking rivers with O. mykiss (pers obs.). Every effort should be made to prevent the further invasion of rivers in TNP by alien fish. Precautionary steps taken should include prohibition of all alien species introductions into rivers in the area, and wherever possible, the undertaking of rehabilitation projects involving alien fish removal. Furthermore, a barrier weir should be constructed in the Palmiet River where it leaves TNP to prevent the movement of alien fish into the park from lower in the river system.

\section{Acknowledgements}

Conservation staff of TNP are thanked for their assistance during sample collection. Special thanks are due to Mr. J. Allan who facilitated sampling in remote areas in the Tsitsikamma mountains, Mr. E. Kivett for assistance in the field, Mr. R. Bills for the loan of field equipment, and identification and curation of specimens. Staff of the South African Institute for Aquatic Biodiversity, and Albany Museum, are thanked for the provision of museum records on fish distribution in the Keurbooms River catchment.

\section{References}

Cambray, J.A., A. BoK \& R. Smith. 1995. Range extensions for Galaxias zebratus Castelnau, 1861 (Galaxiidae), Krom and Gamtoos river systems, Eastern Cape. South African Journal of Aquatic Science 21 (1/2): 99-102.

DeMoor, I.J. \& M.N. Bruton. 1988. Atlas of alien and translocated indigenous aquatic animals in southern Africa. Pretoria: Council for Scientific and Industrial Research, National Scientific Programmes Unit. (South African National Scientific Programmes report; no. 144.)

Gelderblom, C. \& L. Rowlinson. 1999. Management plan for alien vegetation in the Keurbooms catchment. Pretoria: Council for Scientific and Industrial Research.

Hey, S.A. 1926. Fisheries Survey 1925-6. Inland waters. Report No. 1. Department of Mines and Industries. Pretoria: Government Printers.
Hilton-TAYlor, C. 2000. 2000 IUCN Red List of threatened species. Gland, Switzerland: IUCN.

IMPSON, N.D., I.R. BILls \& J.A. CAMBRAY. 2001. A conservation plan for the unique and highly threatened freshwater fishes of the Cape Floral Kingdom. Pp 432-440. In: Collares-Pereira, M.J., I.G. CowX \& M.M. CoElho (eds.). Conservation of freshwater fish: options for the future. Oxford: Blackwell Science.

Le Roi Le Riche, H. \& D. Hey. 1947. Survey of the south western districts. Cape Town: Inland Fisheries Department, Provincial Administration of the Cape of Good Hope. (Report No 4: 19-27).

MolL, E.J. \& L. Bossi. 1984. Vegetation map of the fynbos biome. Mowbray: Director of Survey and Mapping.

RusSELL, I.A. 1998. Freshwater fish of the Addo Elephant National Park. South African Journal of Aquatic Science 24 (1/2): 57-70.

Russell, I.A. 1999. Freshwater fish of the Wilderness National Park. Koedoe 42(1): 73-78.

Russell, I.A. 2001. Freshwater fishes of Bontebok National Park. Koedoe. 44(2): 71-77.

ScotT, H.A. \& K.C.D. Hamman. 1984. Freshwater fishes of the Cape. Cape Town: Cape Department of Nature and Environmental Conservation. (Cape Conservation series no. 5.)

Skelton, P.H. 1980. Systematics and biogeography of the redfin Barbus species (Pisces: Cyprinidae) from southern Africa. Unpublished Ph.D. thesis. Rhodes University, Grahamstown.

Skelton, P.H. 1987. South African Red Data BookFishes. Pretoria: Council for Scientific and Industrial Research, National Scientific Programmes Unit. (South African National Scientific Programmes report; no. 137.)

Skelton, P.H. 1988. A taxonomic revision of the redfin minnows (Pisces, Cyprinidae) from southern Africa. Annals of the Cape Provincial Museum 16(10): 201-307.

SkeLton, P.H. 1993. A complete guide to the freshwater fishes of southern Africa. Halfway House: Southern Book Publishers.

Skelton, P.H. 1994. Baseline survey of fishes in the Keurbooms/Bietou and Piesang Rivers, Southern Cape. Pretoria: Department of Water Affairs and Forestry. (Plettenberg Bay Coastal Catchment Study).

Skelton, P.H., J.A. Cambray, A. Lombard \& G.A. BENN. 1995. Patterns of distribution and conservation status of freshwater fishes in South Africa. South African Journal of Zoology 30(3): 711-781.

Sмith, J.L.B. \& M.M. Sмith. 1966. Fishes of the Tsitsikamma Coastal National Park. Pretoria: National Parks Board of Trustees.

Von Breitenbach, F. 1974. Southern Cape forests and trees. Pretoria: Government Printers. 